\title{
Expression of the prolyl isomerase Pin1 is a useful indicator of sensitivity to chemoradiotherapy in advanced esophageal squamous cell carcinoma
}

\author{
MINORU FUKUCHI, YASUYUKI FUKAI, MAKOTO SOHDA, TATSUYA MIYAZAKI, \\ MASANOBU NAKAJIMA, TAKANORI INOSE, NARITAKA TANAKA, \\ KATSUHIKO TSUKADA, HIROYUKI KATO and HIROYUKI KUWANO \\ Department of General Surgical Science, Gunma University Graduate School of Medicine, \\ 3-39-22, Showa-machi, Maebashi, Gunma 371-8511, Japan
}

Received November 27, 2008; Accepted December 30, 2008

DOI: 10.3892/or_00000294

\begin{abstract}
Cell cycle regulators, such as cyclinD1 and p53, play major roles in the tumor response to radiation and chemotherapy in esophageal squamous cell carcinoma (SCC). Pin1-mediated prolyl-isomerization potentiates cell cycle progression and cell proliferation, including the regulation of cyclinD1 and p53. Herein, we investigated the effect of Pin 1 in association with cyclinD1 and p53 on the sensitivity of esophageal SCC to chemoradiotherapy (CRT). The expression levels of Pin1, cyclinD1 and p53 were examined immunohistochemically in endoscopic biopsy specimens from 68 advanced esophageal SCC patients before CRT to determine whether their expression levels predicted the clinical effectiveness of CRT in individual cancers. Fortysix of the 68 patients $(67.6 \%)$ had an effective response to CRT, whereas 22 patients $(32.4 \%$ ) had an ineffective response. There was no significant correlation between clinical responses and expression levels of cyclinD1 or p53. However, the clinical response of the high Pin1 expression group was significantly higher than that of the low expression group $(\mathrm{P}=0.0200)$. Moreover, our data indicate that the combined immunohistochemical evaluation of Pin1, cyclinD1 and p53 expression in pretreatment biopsy samples is a useful indicator of sensitivity to CRT in advanced esophageal SCC. Thus, Pin1 may influence cyclinD1 and p53 functions and predict CRT sensitivity.
\end{abstract}

\section{Introduction}

Esophageal cancer has one of the highest malignant potentials among gastrointestinal neoplasms. Despite recent improvements in surgical techniques, the prognosis of patients with

Correspondence to: Dr Minoru Fukuchi, Department of General Surgical Science, Gunma University Graduate School of Medicine, 3-39-22, Showa-machi, Maebashi, Gunma 371-8511, Japan E-mail: mfukuchi@med.gunma-u.ac.jp

Key words: Pin1, cyclinD1, p53, esophageal squamous cell carcinoma, chemoradiotherapy advanced esophageal cancer remains poor (1). Chemoradiotherapy (CRT) for esophageal cancer has been investigated since the 1980s, and the combination of 5-FU and cisplatin has been regarded as enhancing radiosensitivity (2). Previous studies on CRT as a definitive treatment have indicated various advantages in esophageal cancer (3-5). Thus, CRT is potentially an alternative to surgery, and investigating useful and sensitive indicators of the response to CRT in esophageal cancer is very important.

Advances in molecular biology have revealed many biologic markers related to the effectiveness of CRT in esophageal cancer. The extent of apoptosis correlates well with the response to radiation therapy and is affected by a variety of genes. The $p 53$ gene plays a major role in radiationinduced apoptosis, because many studies have shown apoptosis to be increased by wild-type p53, but decreased by its mutation $(6,7)$. Moreover, chemotherapy and radiotherapy are generally effective against tumor cells that have a high proliferative index. Indeed, tumors that respond best to radiation have a high Ki-67 index, a proliferation-associated marker (8-10). Furthermore, cyclinD1 overexpression is thought to accelerate the cell cycle, and is correlated with an increased cell proliferative index in esophageal cancer (11).

Oncogenesis comprises a complex series of multi-factorial processes that result in uncontrolled cell proliferation. One pivotal signaling mechanism that controls many cellular growth processes is the phosphorylation of proteins on serine/threonine residues preceding proline (Ser/Thr-Pro) $(12,13)$. The Ser/Thr-Pro motifs present in a certain subset of phosphoproteins are specifically isomerized by the peptidylprolyl cis-trans isomerase Pin1 (14-17). Pin1-mediated prolylisomerization has been shown to potentiate the function of several oncogenic pathways. Pin1 elevates cyclinDl gene expression by activating the c-jun/AP-1 and $\beta$-catenin/TCF transcription factors $(18,19)$. Moreover, Pin1 is involved in the DNA damage response through modulation of p53 functions upon genotoxic stress $(20,21)$. Pin 1 thus plays an important role in many pivotal cellular events, such as cell cycle progression, cell proliferation and oncogenesis.

Previous studies have indicated that Pin 1 is highly overexpressed in several human cancers and that its expression levels parallel the malignant properties of tumors $(18,19,22-24)$. 
We also reported that Pin1 expression is correlated with tumor progression and poor prognosis in patients with esophageal squamous cell carcinoma (SCC) (25). In the present study, we evaluated the role of Pin1 as a regulator of cyclinD1 and p53, which influence the sensitivity of esophageal SCCs to CRT, in biopsy specimens obtained before CRT. We also determined whether the expression pattern of Pin 1 could predict the clinical effectiveness of CRT in individual esophageal SCCs.

\section{Materials and methods}

Patients and samples. The study population consisted of 68 patients (59 males and 9 females) with esophageal SCC who had undergone pretreatment CRT at the Department of General Surgical Science, Gunma University Graduate School of Medicine, between 1995 and 2003, and for whom biopsy specimens were available for re-examination. The age of the patients ranged from 42 to 86 years with a mean age of 66.5 years. The tumors were staged according to the sixth edition of the TNM classification of the International Union Against Cancer (26). All biopsy specimens were obtained before the start of CRT. All specimens were fixed in formalin, embedded in paraffin, and sectioned at a thickness of $4 \mu \mathrm{m}$. The samples were examined after hematoxylin and eosin (H\&E) staining, and immunohistochemical studies were also performed. Patients were divided into three groups: complete response (CR), partial response (PR), and no response (no change, $\mathrm{NC}$; and progressive disease, PD). Responses to CRT were evaluated by barium esophagography, endoscopy, and computed tomography according to the Guidelines for the Clinical and Pathologic Studies on Carcinoma of the Esophagus (2007) (27). Three or four weeks after the last cycle of CRT, 13 of the 68 patients underwent esophagectomy combined with resection of regional lymph nodes.

Radiation and chemotherapy. Our radiation therapy treatment policy for esophageal carcinoma was to perform external beam irradiation of the primary tumor, the mediastinum and neck at a total dose of 40 Gy through anterior-posterior and posterior-anterior opposite fields. Then, an additional 20-30 Gy boost for a total dose of 60-70 Gy was delivered to tumors with oblique opposite shrunken fields to avoid irradiation of the spinal cord. Radiation therapy was performed with a linear accelerator using a 10-MV photon beam at a total dose of $40 \mathrm{~Gy}$ for preoperative cases and 60-70 Gy for inoperative cases. The dose was fractionated into 2 Gy daily, 5 fractions per week. One course of concurrent chemotherapy consisted of daily administration of 5-fluorouracil at $350-500 \mathrm{mg} / \mathrm{m}^{2}$ as a continuous intravenous infusion over $24 \mathrm{~h}$. The fluorouracil was administered 5 days a week for 4 weeks. Cisplatin or nedaplatin at $80 \mathrm{mg} / \mathrm{m}^{2}$ was infused intravenously over a $2-\mathrm{h}$ period, once, on day 1 . In inoperative cases, we performed two courses of this regimen. The CRT protocol described above has been used previously (28).

Immunohistological staining procedure and evaluation of staining. Immunohistochemical staining of biopsy specimens was performed by the standard avidin-biotin peroxidase complex method described previously (25). Briefly, sections were incubated with anti-Pin1 polyclonal antibody (Santa Cruz Biotechnology, Inc., Santa Cruz, CA) at a dilution of 1:200, anti-cyclinD1 monoclonal antibody (clone P2D11F11, Novocastra Laboratories Ltd., Newcastle, UK) at a dilution of 1:50, and anti-p53 monoclonal antibody (clone DO7, Novocastra) at a dilution of 1:100. A negative control was prepared by substituting normal rabbit and mouse serum for each primary antibody. No staining was detected in any control section.

Pin1 immunostaining was evaluated visually and semiquantified by two of the authors (M.F. and Y.F.) in a coded manner, and then scored for the degree of expression. Normal squamous mucosa was always used as a positive control to ensure the quality of the immunostaining. Pin1 staining was classified as high (staining in $67-100 \%)$ or low (0-67\%) based on the percentage of the tumor cells that were immunopositive and also the intensity of the staining, as described previously (25). CyclinD1 staining was classified as high when $>10 \%$ of the tumor cells were positive and low when $<10 \%$ of the tumor cells were positive. Evaluation of p53 staining was classified as positive when $>40 \%$ of tumor cells were stained and negative when $<40 \%$ of tumor cells were stained. Overexpression of p53 protein, for which $>40 \%$ of tumor cells were stained, indicated that the patient had a mutant p53 gene, therefore we divided p53 expression into two groups at the $40 \%$ expression level (28).

As each of the Pin1-high, cyclinD1-high and p53-negative groups showed a higher CRT response than its counterpart, CRT sensitivity was scored as the number of these highsensitivity subgroups. Pin 1 high staining scored 1 and Pin1 low staining scored 0 . CyclinD1 high staining scored 1 and cyclinD1 low staining scored 0 . p53 positive staining scored 1 and p53 negative staining scored 0 . Thus, tumors were classified into 3 groups, a high-score group (score 3 ), a middle-score group (score 2) and a low-score group (score 0 or 1 ), following the addition of points from each expression profile (28).

Statistical analysis. Statistical analysis was performed using the $\chi^{2}$ test, Fisher's exact test, the Mann-Whitney test, and ANOVA method. Survival curves of the patients were calculated using the Kaplan-Meier method, and analysis was performed using the log-rank test in a univariate analysis. Statistical significance in this study was set as $\mathrm{P}<0.05$.

\section{Results}

CRT effectiveness and patient characteristics. Forty-six of the 68 patients $(67.6 \%)$ had an effective $(\mathrm{CR}+\mathrm{PR})$ response to CRT, whereas 22 patients $(32.4 \%)$ had an ineffective response. No significant differences in patient characteristics were noted between the effective and ineffective groups (Table I).

Correlations between Pinl expression and clinicopathological features. In the normal squamous epithelium of the esophagus, Pin1 immunostaining was predominantly detected in the nuclei of terminally differentiated basal keratinocytes (Fig. 1A). In cases of primary esophageal SCC, Pin1 staining was predominantly present in the nucleus, but also detected 
A

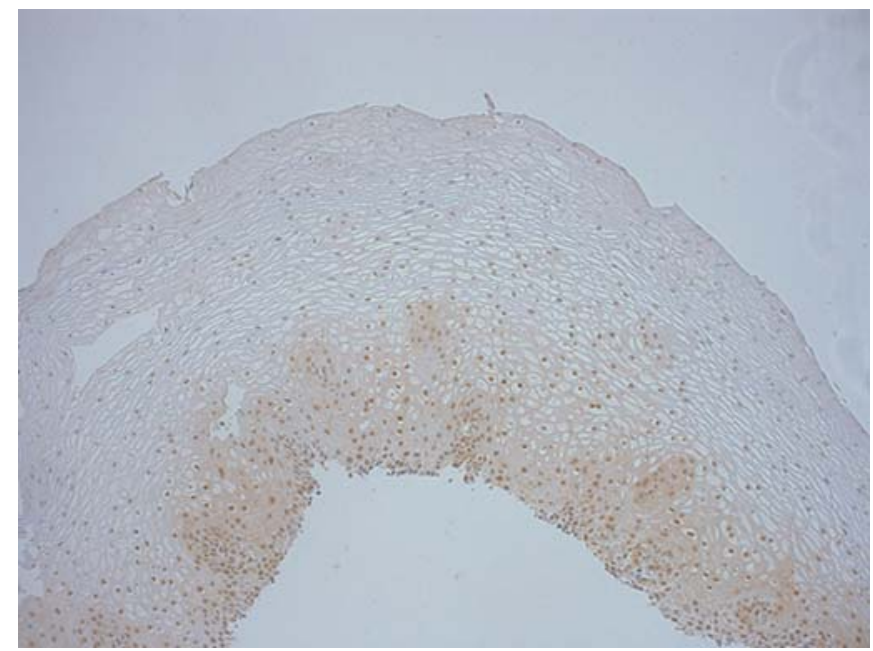

$\mathbf{B}$

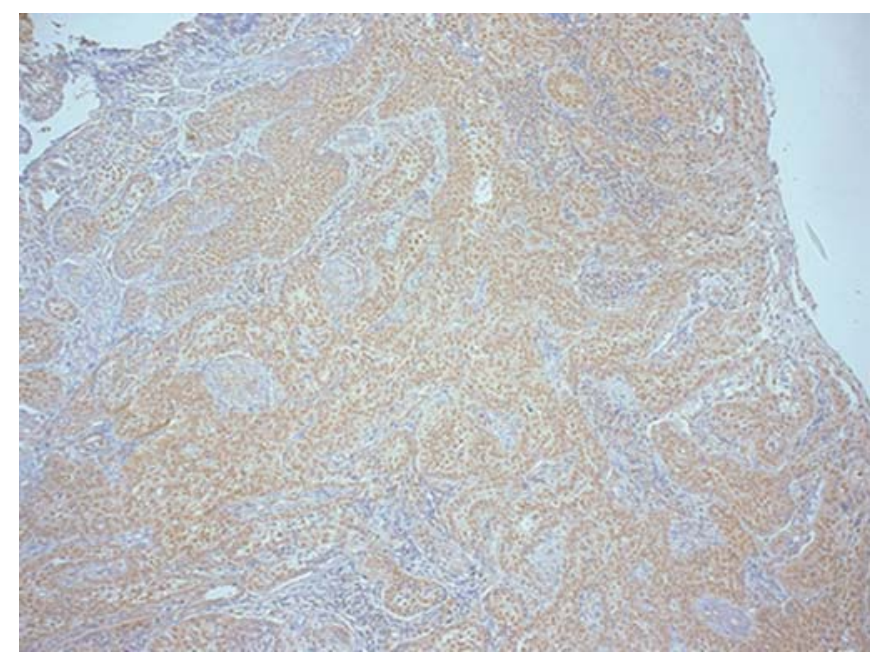

C

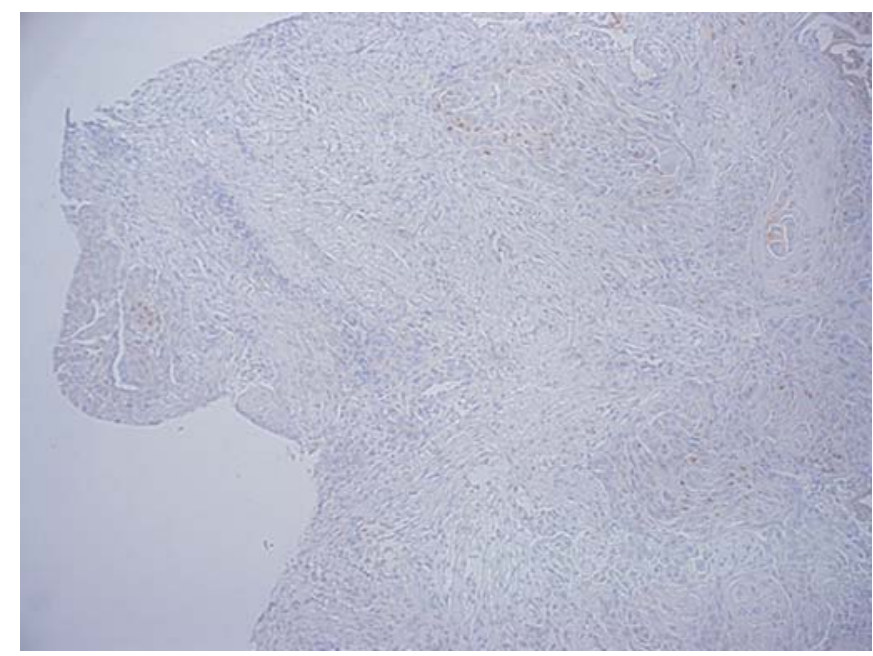

Figure 1. Photographs of biopsy specimens immunostained for Pin1 (x100). (A) Normal esophageal epithelium with Pin1 expression. (B) Esophageal squamous carcinoma with high expression of Pin1. (C) Esophageal squamous carcinoma with low expression of Pin1. in the cytoplasm. Overexpression of Pin1 was found in 25 of 68 patients $(36.8 \%)$ with primary esophageal cancer (Fig. 1B). The remaining patients (43/68: 63.2\%) showed weak Pin1 expression (Fig. 1C).

Comparisons of Pin 1 expression levels in biopsy specimens and clinicopathological characteristics revealed no significant association between Pin1 expression level and patient age, gender, tumor location, tumor differentiation, depth of invasion, lymph node metastasis, distant metastasis or pathologic stage (Table II). Moreover, the survival rates of patients with low and high Pin1 expression did not differ significantly (data not shown).

Correlations between Cyclin D1 and p53 expression and clinicopathological features. CyclinD1 immunoreactivity was detected in 37 of the 68 patients (54.4\%), and p53 immunoreactivity was detected in $27(39.7 \%)$. There was no significant association between $\mathrm{p} 53$ or cyclinD1 expression levels and any of the clinicopathological characteristics examined, and there was no significant difference in survival rates between patients with and without cyclinD1 or p53 expression (data not shown).

Clinical responses and expression of Pin1, cyclinD1 and p53. The relationships between Pin1, cyclinD1 and p53 expression and CRT responses are summarized in Table III. We found that $40.0 \%(10 / 25)$ of the Pin 1 high group had a complete response to CRT, in comparison with only $14.0 \%$ (6/43) of the Pin1 low group. The clinical response of the high Pin1 expression group was significantly higher than that of the low expression group $(\mathrm{P}=0.0200)$. A statistically significant and positive correlation was observed between Pin1 expression and the effect of CRT on esophageal SCC. There was no significant correlation between the clinical response and the expression levels of cyclinD1 or p53. Moreover, Fig. 2 shows the clinical responses in patients with various Pin1, cyclinD1 and p53 combinations. Group A patients showed none or one of the following staining patterns: Pin1 high, cyclinD1 high and p53-negative staining. Group B patients showed two of these staining patterns. Group $\mathrm{C}$ patients showed all. For the combination of Pin1, cyclinD1 and p53 staining, there were significant differences between groups $\mathrm{A}$ and $\mathrm{C}(\mathrm{P}=0.0495)$. In particular, group $\mathrm{C}$ patients showed a higher $\mathrm{CR}$ rate $(50 \%)$ than group A and group B patients.

\section{Discussion}

Pin 1 has been shown to play an important role in multiple steps in oncogenic signaling pathways (18-25). For example, Pin 1 collaborates with Ras signaling to increase the transcriptional activity of c-Jun toward cyclinD1 (18). Pin1 activates $B$-catenin, which can induce the transcription of both cyclinD1 and c-Myc (19). Furthermore, Pin1 is involved in the DNA damage response through modulation of p53 functions upon genotoxic stress $(20,21)$. Moreover, Pin1 is overexpressed in human breast and oral cancers, and high Pin1 expression is correlated with tumor development and poor prognosis in patients with prostate cancer (22-24). We also reported that Pin 1 overexpression was associated with tumor progression and poor prognosis in patients with esophageal SCC (25). 
Table I. The effectiveness of CRT and patients characteristics.

\begin{tabular}{|c|c|c|c|c|}
\hline Parameters & $\begin{array}{l}\text { Effective } \\
(n=46)\end{array}$ & $\begin{array}{l}\text { Ineffective } \\
\quad(n=22)\end{array}$ & Total & P-value \\
\hline Age (mean $\pm \mathrm{SD} ;$ yrs $)$ & $66.7 \pm 1.5$ & $66.1 \pm 2.0$ & & 0.8159 \\
\hline Gender & & & & 0.4855 \\
\hline Male & $39(66.1)$ & $20(33.9)$ & 59 & \\
\hline Female & $7(77.8)$ & $2(22.2)$ & 9 & \\
\hline Radiation dose & $58.9 \pm 1.5$ & $57.5 \pm 2.7$ & & 0.6210 \\
\hline Location & & & & 0.4109 \\
\hline Upper & $10(62.5)$ & $6(37.5)$ & 16 & \\
\hline Midthoracic & $23(63.9)$ & $13(36.1)$ & 36 & \\
\hline Lower & $13(81.3)$ & $3(18.7)$ & 16 & \\
\hline Differentiation & & & & 0.9083 \\
\hline Well & $8(72.7)$ & $3(27.3)$ & 11 & \\
\hline Moderate & $23(65.7)$ & $12(34.3)$ & 35 & \\
\hline Poor & $15(68.2)$ & $7(31.8)$ & 22 & \\
\hline \multicolumn{5}{|l|}{ TNM classification $^{\mathrm{a}}$} \\
\hline $\mathrm{T}$ & & & & 0.2512 \\
\hline $\mathrm{T} 2$ & $6(85.7)$ & $1(14.3)$ & 7 & \\
\hline $\mathrm{T} 3$ & $20(74.1)$ & $7(25.9)$ & 27 & \\
\hline $\mathrm{T} 4$ & $20(58.8)$ & $14(41.2)$ & 34 & \\
\hline $\mathrm{N}$ & & & & 0.5076 \\
\hline No & $14(73.7)$ & $5(26.3)$ & 19 & \\
\hline N1 & $32(65.3)$ & $17(34.7)$ & 49 & \\
\hline M & & & & 0.7889 \\
\hline M0 & $32(66.7)$ & $16(33.3)$ & 48 & \\
\hline M1 & $14(70.0)$ & $6(30.0)$ & 20 & \\
\hline Stage & & & & 0.4388 \\
\hline II & $9(81.8)$ & $2(18.2)$ & 11 & \\
\hline III & $20(69.0)$ & $9(31.0)$ & 29 & \\
\hline IV & $17(60.7)$ & $11(39.3)$ & 28 & \\
\hline
\end{tabular}

anternational Union Against Cancer TNM classification of malignant tumors. SD, standard deviation (\%).

CyclinD1 and p53 are known to be associated with the sensitivity of esophageal SCC to CRT (29-33), but the details of their influences, as well as the effects of Pin1, remain unclear. In the present study, we evaluated the role of Pin1 as a regulator of cyclinD1 and $\mathrm{p} 53$ in sensitivity to CRT, in biopsy specimens of esophageal SCC, by immunohistochemistry. We found a statistically significant positive correlation between Pin1 expression and the effect of CRT on esophageal SCC (Table III). Thus, Pin1 appeared to be a significant marker for predicting CRT sensitivity. However, there was no significant correlation between Pin 1 expression and the Ki-67 index or apoptotic index (data not shown).

G1 progression was evaluated by the investigation of cyclinD1 expression. CyclinD1, which is frequently overexpressed in esophageal SCC, is the most crucial regulator of the G1 checkpoint (34). There have been a few studies showing
cyclinD1 expression to be associated with high susceptibility to CRT $(29,33)$. Such a trend was not statistically significant in this study. The total cell proliferative activity was elevated by Ki-67 expression, which was strongest in the S phase, and which is observed in cell cycle phases other than G0. Generally, the CRT response cases had a high Ki-67 index, and therefore a larger population of cycling cells than cases with a low Ki-67 index (8-10,33). However, the difference was not statistically significant in our study (data not shown).

DNA damaging therapy, such as CRT, induces p53, which regulates the cell cycle at the G1 phase. Furthermore, because wild-type p53 protein induces apoptosis in cells with gene abnormalities, some investigations have suggested that $p 53$ gene status is a useful indicator for predicting CRT sensitivity $(6,7,35)$. Generally, p53-positive tumors are associated with a poorer response to CRT than p53-negative (functional) tumors 
Table II. The correlation between clinicopathological characteristics and Pin1 expression.

\begin{tabular}{|c|c|c|c|c|}
\hline Parameters & $\begin{array}{l}\text { Pin1 low } \\
(n=43)\end{array}$ & $\begin{array}{l}\text { Pin1 high } \\
\quad(n=25)\end{array}$ & Total & P-value \\
\hline Age $($ mean \pm SD; yrs $)$ & $66.1 \pm 1.4$ & $67.2 \pm 2.2$ & & 0.6603 \\
\hline Gender & & & & 0.8187 \\
\hline Male & $37(62.7)$ & $22(37.3)$ & 59 & \\
\hline Female & $6(66.7)$ & $3(33.3)$ & 9 & \\
\hline Location & & & & 0.3543 \\
\hline Upper & $12(75.0)$ & $4(25.0)$ & 16 & \\
\hline Midthoracic & $20(55.6)$ & $16(44.4)$ & 36 & \\
\hline Lower & $11(68.8)$ & $5(31.2)$ & 16 & \\
\hline Differentiation & & & & 0.7462 \\
\hline Well & $8(72.7)$ & $3(27.3)$ & 11 & \\
\hline Moderate & $21(60.0)$ & $14(40.0)$ & 35 & \\
\hline Poor & $14(63.6)$ & $8(36.4)$ & 22 & \\
\hline \multicolumn{5}{|l|}{ TNM classification $^{\mathrm{a}}$} \\
\hline $\mathrm{T}$ & & & & 0.8893 \\
\hline $\mathrm{T} 2$ & $5(71.4)$ & $2(28.6)$ & 7 & \\
\hline $\mathrm{T} 3$ & $17(63.0)$ & $10(37.0)$ & 27 & \\
\hline $\mathrm{T} 4$ & $21(61.8)$ & $13(38.2)$ & 34 & \\
\hline $\mathrm{N}$ & & & & 0.5695 \\
\hline No & $11(57.9)$ & $8(42.1)$ & 19 & \\
\hline N1 & $32(65.3)$ & $17(34.7)$ & 49 & \\
\hline M & & & & 0.1440 \\
\hline M0 & $33(68.8)$ & $15(31.3)$ & 48 & \\
\hline M1 & $10(50.0)$ & $10(50.0)$ & 20 & \\
\hline Stage & & & & 0.3368 \\
\hline II & 7 (63.6) & $4(36.4)$ & 11 & \\
\hline III & $21(72.4)$ & 8 (27.6) & 29 & \\
\hline IV & $15(53.6)$ & $13(46.4)$ & 28 & \\
\hline
\end{tabular}

anternational Union Against Cancer TNM classification of malignant tumors. SD, standard deviation (\%).

Table III. Pin1, cyclinD1, p53 and response to esophageal cancer to CRT.

\begin{tabular}{lrrrr}
\hline & \multicolumn{3}{c}{ Response to CRT } & \\
\cline { 2 - 4 } & CR & PR & NC/PD & P-value \\
\hline Pin1 & & & & 0.0200 \\
Low & 6 & 19 & 18 & \\
High & 10 & 11 & 4 & \\
CyclinD1 & & & & 0.1687 \\
Low & 8 & 10 & 13 & \\
High & 8 & 20 & 9 & \\
p53 & & & & 0.5501 \\
$\quad$ Negative & 11 & 19 & 11 & \\
Positive & 5 & 11 & 11 & \\
\hline
\end{tabular}

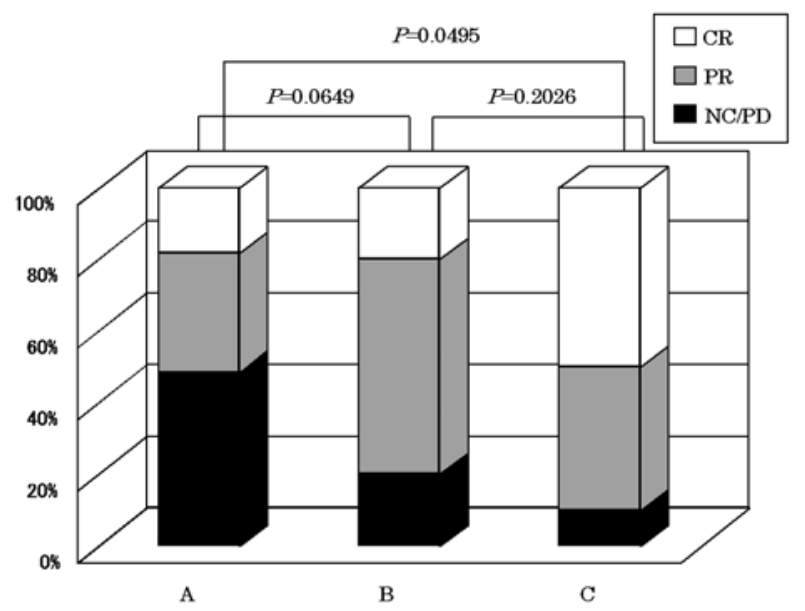

Figure 2. Clinical response in 68 esophageal cancer patients with various Pin1, cyclinD1 and p53 expression levels, classified by tumor sensitivity score. (A) Patients with scores of 0 or 1. (B) Patients with a score of 2. (C) Patients with a score of 3 . 
(30-33). However, such a trend related to p53 or the apoptotic index was not statistically significant in the present study (data not shown).

Although cyclinD1 and p53 play major roles in G1 progression, Pin1 is also required for G2-M progression and the DNA checkpoint (36-38). Pin1 thus plays an important role in pivotal cellular events, such as cell cycle progression and cell proliferation. The effects on CRT sensitivity caused by Pin1 expression may result from cell cycle progression through the whole phase. However, cyclinD1 and p53 levels are reported to be correlated with the sensitivity of esophageal SCC to CRT (29-33). Pin1 is a regulator of cyclinD1 and p53, and may influence cyclinD1 and p53 and predict CRT sensitivity (18-21). Including an assessment of Pin1 expression with a combined assessment of cyclinD1 and p53 expression might provide the clearest indicator of response to CRT, and could make it possible to predict responses in those patients in whom the combination of cyclinD1 and p53 expression alone is an inadequate predictor (Fig. 2).

In conclusion, pretreatment evaluation of Pin1 expression is a useful and sensitive indicator of response to CRT in esophageal SCC. To predict the impact of CRT, it is also important to evaluate combined Pin1, cyclinD1 and p53 expression. Moreover, Pin1 overexpression was correlated with tumor progression in patients with esophageal SCC (25). Thus, advanced esophageal SCC patients with Pin1 overexpression should be especially considered to undergo not only curative surgery, but also radiation and chemotherapy before or after surgery.

\section{References}

1. Sugimachi K, Watanabe M, Sadanaga N, Ikebe M, Kitamura K, Mori $\mathrm{M}$ and Kuwano $\mathrm{H}$ : Recent advances in the diagnosis and surgical treatment of patients with carcinoma of the esophagus. J Am Coll Surg 178: 363-368, 1994.

2. Byfield JE: Combined modality infusional chemotherapy with radiation. In: Cancer Chemotherapy by Infusion. Lokich JJ (ed). 2nd edition, Percepta Press, Chicago, IL, pp521-551, 1990.

3. Coia LR: Chemoradiation as primary management of esophageal cancer. Semin Oncol 21: 483-492, 1994.

4. Forastiere AA, Orringer MB, Perez-Tamayo C, Urba SG and Zahurak M: Preoperative chemoradiation followed by transhiatal esophagectomy for carcinoma of the esophagus: final report. J Clin Oncol 11: 1118-1123, 1993.

5. Ohtsu A, Yoshida S, Boku N, Fujii T, Miyata Y, Hosokawa K, Koba I, Shimizu W and Ogino T: Concurrent chemotherapy and radiation therapy for locally advanced carcinoma of the esophagus. Jpn J Clin Oncol 25: 261-266, 1995.

6. Lowe SW, Schmitt EM, Smith SW, Osborne BA and Jacks T: p53 is required for radiation-induced apoptosis in mouse thymocytes. Nature 362: 847-849, 1993.

7. Clarke AR, Purdie CA, Harrison DJ, Morris RG, Bird CC, Hooper ML and Wyllie AH: Thymocyte apoptosis induced by p53dependent and independent pathways. Nature 362: 849-852, 1993

8. Mendonca MS, Rodriguez A and Alpen EL: Quiescence in 9L cells and correlation with radiosensitivity and PLD repair. Radiat Res 117: 433-447, 1989

9. Masunaga S, Ono K and Abe M: A method for the selective measurement of the radiosensitivity of quiescent cells in solid tumors - combination of immunofluorescence staining to BrdU and micronucleus assay. Radiat Res 125: 243-247, 1991.

10. Okuno Y, Nishimura Y, Kashu I, Ono K and Hiraoka M Prognostic values of proliferating cell nuclear antigen (PCNA) and $\mathrm{Ki}-67$ for radiotherapy of oesophageal squamous cell carcinomas. Br J Cancer 80: 387-395, 1999.

11. Shamma A, Doki Y, Shiozaki H, Tsujinaka T, Inoue M, Yano M, Kimura Y, Yamamoto M and Monden M: Effect of cyclin D1 and associated proteins on proliferation of esophageal squamous cell carcinoma. Int J Oncol 13: 455-460, 1998.
12. Blume-Jensen $P$ and Hunter T: Oncogenic kinase signalling. Nature 411: 355-365, 2001.

13. Hanahan D and Weinberg RA: The hallmarks of cancer. Cell 100: 57-70, 2000

14. Lu KP, Hanes SD and Hunter T: A human peptidyl-prolyl isomerase essential for regulation of mitosis. Nature 380: 544-547, 1996.

15. Lu KP, Liou YC and Zhou XZ: Pinning down proline-directed phosphorylation signaling. Trends Cell Biol 12: 164-172, 2002.

16. Yaffe MB, Schutkowski M, Shen M, Zhou XZ, Stukenberg PT, Rahfeld JU, Xu J, Kuang J, Kirschner MW, Fischer G, Cantley LC and Lu KP: Sequence-specific and phosphorylationdependent proline isomerization: a potential mitotic regulatory mechanism. Science 278: 1957-1960, 1997.

17. Ranganathan R, Lu KP, Hunter T and Noel JP: Structural and functional analysis of the mitotic rotamase Pin 1 suggests substrate recognition is phosphorylation dependent. Cell 89: 875-886, 1997.

18. Wulf GM, Ryo A, Wulf GG, Lee SW, Niu T, Petkova V and Lu KP: Pin 1 is overexpressed in breast cancer and cooperates with Ras signaling in increasing the transcriptional activity of c-Jun towards cyclin D1. EMBO J 20: 3459-3472, 2001.

19. Ryo A, Nakamura M, Wulf G, Liou YC and Lu KP: Pin1 regulates turnover and subcellular localization of $\beta$-catenin by inhibiting its interaction with APC. Nat Cell Biol 3: 793-801, 2001.

20. Zheng H, You H, Zhou XZ, Murray SA, Uchida T, Wulf G, Gu L, Tang X, Lu KP and Xiao ZX: The prolyl isomerase Pin 1 is a regulator of p53 in genotoxic response. Nature 419: 849-853, 2002.

21. Zacchi P, Gostissa M, Uchida T, Salvagno C, Avolio F, Volinia S, Ronai Z, Blandino G, Schneider C and Del Sal G: The prolyl isomerase Pin 1 reveals a mechanism to control p53 functions after genotoxic insults. Nature 419: 853-857, 2002.

22. Miyashita H, Mori S, Motegi K, Fukumoto M and Uchida T: Pin1 is overexpressed in oral squamous cell carcinoma and its levels correlate with cyclin D1 overexpression. Oncol Rep 10: 455-461, 2003.

23. Miyashita H, Uchida T, Mori S, Echigo S and Motegi K: Expression status of Pin 1 and cyclins in oral squamous cell carcinoma: Pin1 correlates with Cyclin D1 mRNA expression and clinical significance of cyclins. Oncol Rep 10: 1045-1048, 2003.

24. Ayala G, Wang D, Wulf G, Frolov A, Li R, Sowadski J, Wheeler TM, Lu KP and Bao L: The prolyl isomerase Pin1 is a novel prognostic marker in human prostate cancer. Cancer Res 63: 6244-6251, 2003.

25. Fukuchi M, Fukai Y, Kimura H, Sohda M, Miyazaki T, Nakajima M, Masuda N, Tsukada K, Kato H and Kuwano H: Prolyl isomerase Pin 1 expression predicts prognosis in patients with esophageal squamous cell carcinoma and correlates with cyclinD1 expression. Int J Oncol 29: 329-334, 2006.

26. Sobin $\mathrm{LH}$ and Wittekind $\mathrm{CH}$ : International Union Against Cancer (UICC). TNM Classification of Malignant Tumors. 6th edition, Wiley-Liss, New York, pp10-12, 2002.

27. The Japanese Esophageal Society: Guide Lines for the Clinical and Pathologic Studies on Carcinoma of the Esophagus. 10th edition, Kanehara, Tokyo, 2007.

28. Sohda M, Ishikawa H, Masuda N, Kato H, Miyazaki T, Nakajima M, Fukuchi M, Manda R, Fukai Y, Sakurai H and Kuwano H: Pretreatment evaluation of combined HIF-1alpha, p53 and p21 expression is a useful and sensitive indicator of response to radiation and chemotherapy in esophageal cancer. Int J Cancer 110: 838-844, 2004.

29. Samejima R, Kitajima Y, Yunotani S and Miyazaki K: Cyclin D1 is a possible predictor of sensitivity to chemoradiotherapy for esophageal squamous cell carcinoma. Anticancer Res 19: 5515-5521, 1999.

30. Shimada Y, Watanabe G, Yamasaki S, Maeda M, Kawabe A, Kaganoi JI, Itami A, Fukumoto M, Kanda Y and Imamura M: Histological response of cisplatin predicts patients' survival in oesophageal cancer and $\mathrm{p} 53$ protein accumulation in pretreatment biopsy is associated with cisplatin sensitivity. Eur J Cancer 36: 987-993, 2000.

31. Miyata H, Doki Y, Yamamoto H, Kishi K, Takemoto H, Fujiwara Y, Yasuda T, Yano M, Inoue M, Shiozaki H, Weinstein IB and Monden M: Overexpression of CDC25B overrides radiation-induced G2-M arrest and results in increased apoptosis in esophageal cancer cells. Cancer Res 61: 3188-3193, 2001. 
32. Hironaka S, Hasebe T, Kamijo T, Ohtsu A, Boku N, Yoshida S, Saitoh $\mathrm{H}$ and Ochiai A: Biopsy specimen microvessel density is a useful prognostic marker in patients with $\mathrm{T}(2-4) \mathrm{M}(0)$ esophageal cancer treated with chemoradiotherapy. Clin Cancer Res 8: 124-130, 2002.

33. Takeuchi H, Ozawa S, Ando N, Kitagawa Y, Ueda M and Kitajima M: Cell-cycle regulators and the Ki-67 labeling index can predict the response to chemoradiotherapy and the survival of patients with locally advanced squamous cell carcinoma of the esophagus. Ann Surg Oncol 10: 792-800, 2003.

34. Doki Y, Imoto $M$, Han EK, Sgambato A and Weinstein IB Increased expression of the P27KIP1 protein in human esophageal cancer cell lines that over-express cyclin D1. Carcinogenesis 18: 1139-1148, 1997.
35. Levine AJ, Momand J and Finlay CA: The p53 tumour suppressor gene. Nature 351: 453-456, 1991

36. Zhou XZ, Kops O, Werner A, Lu PJ, Shen M, Stoller G, Kullertz G, Stark M, Fischer G and Lu KP: Pin1-dependent prolyl isomerization regulates dephosphorylation of Cdc25C and tau proteins. Mol Cell 6: 873-883, 2000.

37. Shen M, Stukenberg PT, Kirschner MW and Lu KP: The essential mitotic peptidyl-prolyl isomerase Pin 1 binds and regulates mitosis-specific phosphoproteins. Genes Dev 12: 706-720, 1998.

38. Winkler KE, Swenson KI, Kornbluth S and Means AR: Requirement of the prolyl isomerase Pin 1 for the replication checkpoint. Science 287: 1644-1647, 2000. 